\title{
Microstructure and Mechanical Properties of Ductile Aluminium Alloy Manufactured by Recycled Materials
}

\author{
Hailin Yang ${ }^{1}$, Shouxun $\mathrm{Ji}^{1,{ }^{*}}$, Douglas Watson ${ }^{1,2}$, Mark White ${ }^{2}$, Zhongyun Fan ${ }^{1}$ \\ ${ }^{1}$ BCAST, Brunel University, Uxbridge, Middlesex, UB8 3PH, United Kingdom \\ ${ }^{2}$ Engineering Centre, Jaguar Cars Ltd, Abbey Road, Coventry, CV34 4LF, United Kingdom \\ `shouxun.ji@brunel.ac.uk
}

Keywords: Aluminium alloys, High pressure die casting, Microstructure, Mechanical properties, materials recycling

\begin{abstract}
The present paper introduces the microstructure and mechanical properties of the Al-MgSi-Mn alloy made by recycled materials, in which the impurity levels of iron are mainly concerned. It is found that the increased Fe content reduces the ductility and yield strength but slightly increases the UTS of the diecast alloy. The tolerable Fe content is $0.45 \mathrm{wt} . \%$, at which the recycled alloys are still able to produce castings with the mechanical properties of yield strength over $140 \mathrm{MPa}$, UTS over $280 \mathrm{MPa}$ and elongation over $15 \%$. The Fe content is steadily accumulated in the alloy with the increase of recycle times. However, after 13 cycles, the recycled alloys are still able to produce ductile alloys with satisfied mechanical properties.
\end{abstract}

\section{Introduction}

The application of Al-Mg-Si-Mn alloy in car body structure is attracting an increased attention in recent years because of its high ductility and capability of making thin wall castings [1,3]. The main requirements for the alloy include the yield strength over $140 \mathrm{MPa}$, ultimate tensile strength (UTS) over 280MPa and elongation over $15 \%$ [1]. These have been achieved through the optimised control of alloy composition, casting parameters and solidification process in high pressure die casting (HPDC) [2]. However, the impurities need to be strictly controlled in order to obtain the high quality and good re-productivity of castings. On the other hand, the utilisation of recycled material in the manufacturing of aluminium castings is significant and attractive because the recycled aluminium saves up to $95 \%$ of the energy required for the production of primary alloys $[3,4]$. However, the recycled aluminium alloys always contain a variety of impurities, which are introduced by the contaminations, inclusions, tooling and others from processing of materials manufacturing or from casting operation. Iron is one of the most common impurities in the aluminium alloys used in high pressure die casting.

The detrimental effect of $\mathrm{Fe}$ in aluminium alloys results from the Fe-rich intermetallics formed during solidification due to the low solubility of $\mathrm{Fe}$ in solid aluminium [5]. The Fe-rich intermetallics can initialise the cracks under load and therefore lower the mechanical properties. Although a number of Fe-rich intermetallic compounds have been identified in aluminium alloys, $\alpha$ $\mathrm{AlFeMnSi}$ phase and $\beta$-AlFe phase are the two important intermetallics in the Al-Mg-Si-Mn alloy processed by HPDC [5]. The $\beta$-AlFe phase is more detrimental for the mechanical properties of cast alloys than the $\alpha$-AlFeMnSi because of its needle-shaped morphology. However, it is still not clear for the microstructure and mechanical properties of the diecast alloy made by recycled materials.

Therefore, we attempt to find out the Fe tolerance in the Al-Mg-Si-Mn alloy and to examine the precise accumulation of iron during HPDC using fully recycled materials, followed by the prediction of maximum cycles to produce castings with required mechanical properties. The strengthening mechanism and the relationship between the microstructure and mechanical properties are discussed. 


\section{Experimental}

For making fresh alloy, commercial pure aluminium, magnesium, Al-50wt. \%Si, Al-20wt. \%Mn, and Al-10wt. \% Ti master alloy ingots were weighed at a given proportion to make $10 \mathrm{~kg}$ melt per batch for HPDC. The main alloying elements $\mathrm{Al}, \mathrm{Si}, \mathrm{Fe}, \mathrm{Mn}$ and $\mathrm{Ti}$ were melted and held at $730{ }^{\circ} \mathrm{C}$ for 60 minutes before adding $\mathrm{Mg}$ ingot, which had been preheated to $200^{\circ} \mathrm{C}$. When making recycled alloy, a $40 \mathrm{~kg}$ fresh alloy was made and cast in first run. Then the biscuits and overflows were remelted in a furnace at $730^{\circ} \mathrm{C}$, followed by the adjustment of $\mathrm{Mg}$ to the required content.

For all the experiments, the melts were degassed using $\mathrm{N}_{2}$ before composition analysis. The composition of each alloy was measured with an optical mass spectrometer on a cross section of a $\phi 40 \mathrm{~mm}$ cylindrical casting. At least five spark analyses were performed and the average was taken as the chemical composition of the alloy and further confirmed by ICP tests.

Six ASTM standard tensile samples that include three $6.35 \mathrm{~mm}$ round sample and three square samples were cast in each shot using a $4500 \mathrm{kN}$ cold chamber high pressure die casting machine. The pouring temperatures of the liquid alloy were measured by a K-type thermocouple, usually at $650 \pm 5{ }^{\circ} \mathrm{C}$. All the castings were left in ambient atmosphere and at room temperature for at least 24 hours before testing the mechanical properties.

The microstructure was examined using a Zeiss SUPRA 35VP scanning electron microscope (SEM) equipped with EDX. The quantitative EDX analysis in SEM was performed at an accelerating voltage of $20 \mathrm{kV}$ on a polished sample. In situ spectroscopy calibration was performed in each session of the EDX quantification using pure copper.

\section{Results}

(a) The microstructure and mechanical properties of Al-Mg-Si-Mn ally with different Fe content.
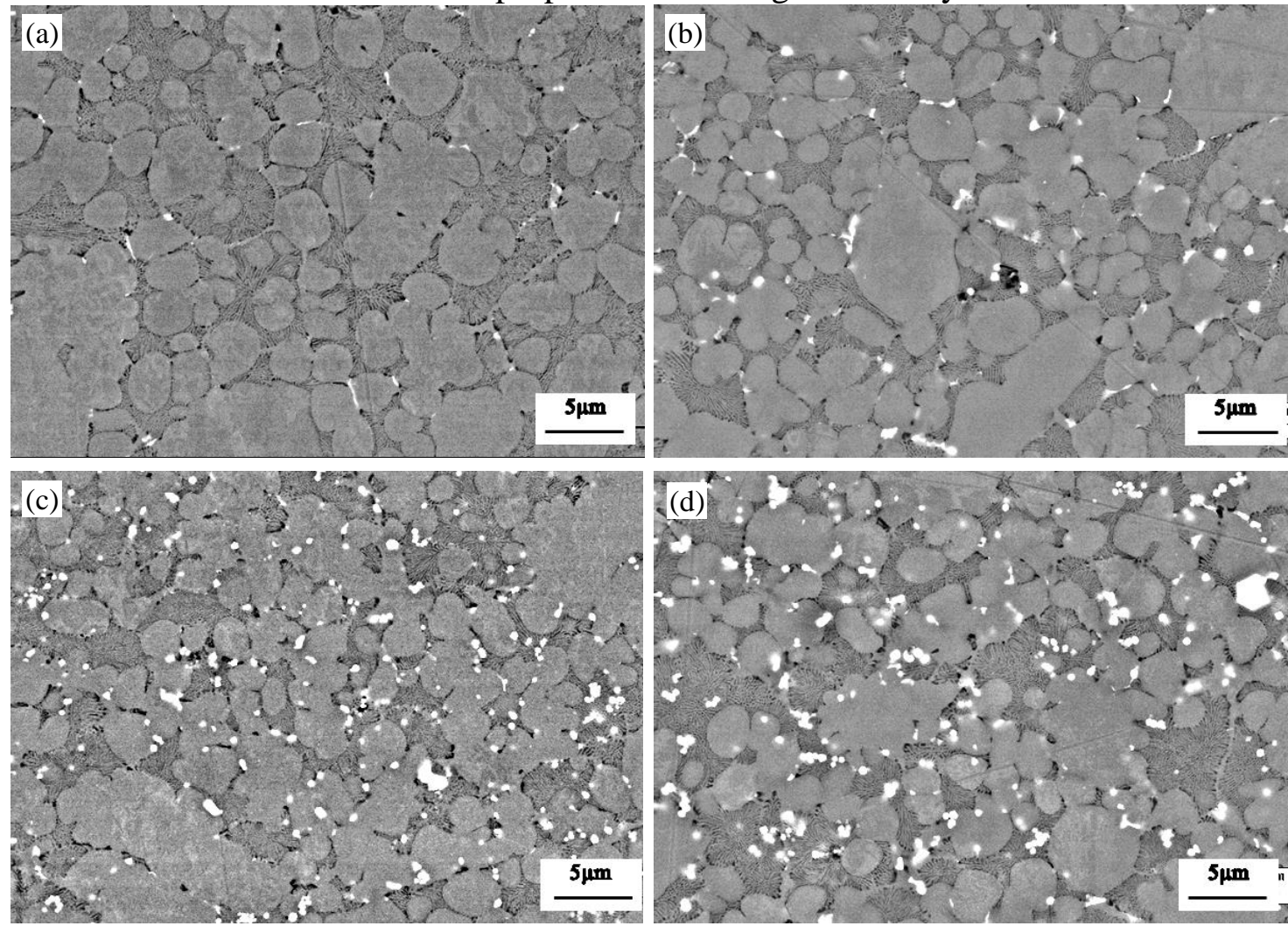

Fig. 1 Backscattered SEM micrographs showing the microstructure of Al-Mg-Si-Mn alloy under ascast condition, (a) $0.08 \mathrm{wt} . \% \mathrm{Fe}$, (b) $0.25 \mathrm{wt} . \% \mathrm{Fe}$, (c) $0.45 \mathrm{wt} . \%$ and (d) $0.52 \mathrm{wt} . \%$.

In order to find out the tolerable amount of Fe impurity in the alloy to satisfy the requirement of mechanical properties, a series of experiments were performed with different Fe levels in the castings of standard tensile samples. The as-cast microstructures are shown in Figs. 1 and 2. It is 
seen no significant change in the morphologies of the primary $\alpha$-Al phase and eutectic phase observed in the alloy containing different levels of Fe. However, in contrast to the primary $\alpha$-Al phase and eutectic phase, the morphologies of Fe-rich compounds were affected by $\mathrm{Fe}$ content. Different morphologies and volume fraction of Fe-rich intermetallics were observed and associated with Fe content. Only a small amount of fine intermetallics were presented in the alloys with up to $0.25 \mathrm{wt} . \% \mathrm{Fe}$. The Fe-rich intermetallics was in irregular morphology when $\mathrm{Fe}$ was $0.08 \mathrm{wt} . \%$, but the regular compact Fe-rich intermetallics were emerged when Fe was 0.25wt.\%. The Fe-rich intermetallics were all in compact morphologies when Fe was over $0.25 \mathrm{wt} \%$. Most of the fine intermetallics were located between the primary $\alpha$-Al phases. The SEM/EDX quantitative analysis (Table 1) identified the irregular Fe-rich phase with the typical composition of the $\alpha-\mathrm{Al}_{15}(\mathrm{Fe}, \mathrm{Mn})_{2} \mathrm{Si}$ phase in the alloy with $0.08 \mathrm{wt} . \% \mathrm{Fe}$ and the fine compact $\mathrm{Fe}$-rich phase with the typical composition of the $\alpha-\mathrm{Al}_{12}(\mathrm{Fe}, \mathrm{Mn})_{3} \mathrm{Si}$ phase in the alloy with over $0.25 \mathrm{wt}$. $\% \mathrm{Fe}$. No other intermetallics were observed in the samples. When the Fe content were increased to $0.45 \mathrm{wt} . \%$ and $0.52 \mathrm{wt} . \%$, there were two types of Fe-rich intermetallics observed. The Fe-rich intermetallics associated with the primary coarse $\alpha-\mathrm{Al}$ phase exhibited coarse compact morphology, which was identified by SEM/EDX with the typical composition of $\alpha-\mathrm{Al}_{12}(\mathrm{Fe}, \mathrm{Mn})_{3} \mathrm{Si}$. Meanwhile, the fine intermetallics were associated with fine $\alpha-\mathrm{Al}$ phase and segregated in the primary $\alpha$-Al grain boundaries, which were identified by $\mathrm{SEM} / \mathrm{EDX}$ quantification to be the same $\alpha$-AlFeMnSi phase with the typical composition of $\alpha$ $\mathrm{Al}_{12}(\mathrm{Fe}, \mathrm{Mn})_{3} \mathrm{Si}$. Therefore, it is clear that the Fe-rich intermetallics contain less Fe in the alloy with very low $\mathrm{Fe}$ content. The increased $\mathrm{Fe}$ content results in the formation of coarse Fe-rich intermetallics in the alloy.
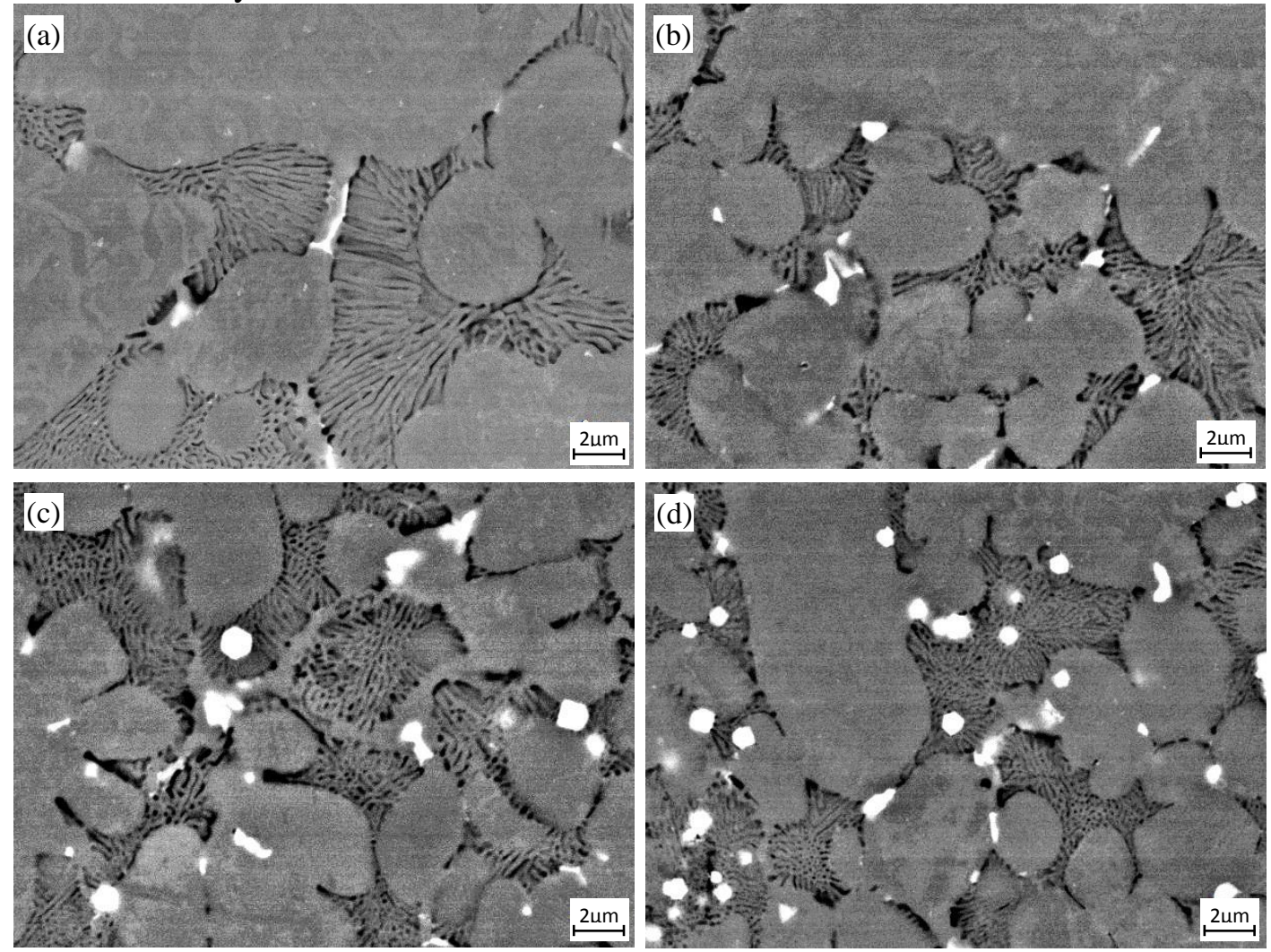

Fig. 2. Backscattered SEM micrographs showing the morphology of Fe-rich phase in the Al-Mg-SiMn alloy (a) $0.08 w t . \%$ Fe, (b) 0.25 wt. \% Fe,(c) $0.45 w t . \%$ and (d) $0.52 w t . \%$.

The mechanical properties of the diecast alloys are presented in Fig. 3 for the effect of Fe content. It is seen a slight decrease in the yield strength and a significant decrease in the elongation with the increase of Fe content in the alloy. However, a slight increase in the ultimate tensile strength (UTS) was observed in the alloy in the experimental range of Fe content. Overall, when Fe level was at $0.45 \mathrm{wt} . \%$, the mechanical properties were still satisfied with the yield strength over 
$140 \mathrm{MPa}$, UTS over $280 \mathrm{MPa}$ and elongation over $15 \%$. This means that the tolerable Fe content in the alloy can be $0.45 \mathrm{wt} . \%$.

Table 1 The composition of Fe-rich intermetallics identified by quantitative SEM/EDX analysis

\begin{tabular}{lllllll}
\hline $\mathrm{Fe}($ wt.\%) & Phase morphology & Identified compound & $\mathrm{Al}$ & $\mathrm{Fe}$ & $\mathrm{Mn}$ & $\mathrm{Si}$ \\
\hline 0.08 & Fine irregular & $\mathrm{Al}_{15}(\mathrm{Fe}, \mathrm{Mn})_{2} \mathrm{Si}$ & 84.7 & 6.0 & 4.2 & 5.1 \\
0.25 & Fine irregular & $\mathrm{Al}_{15}(\mathrm{Fe}, \mathrm{Mn})_{2} \mathrm{Si}$ & 84.4 & 6.3 & 4.1 & 5.2 \\
& Fine compact & $\mathrm{Al}_{12}(\mathrm{Fe}, \mathrm{Mn})_{3} \mathrm{Si}$ & 76.1 & 11.3 & 6.1 & 6.5 \\
0.45 & Fine compact & $\mathrm{Al}_{12}(\mathrm{Fe}, \mathrm{Mn})_{3} \mathrm{Si}$ & 75.4 & 12.2 & 6.3 & 6.1 \\
0.52 & Fine compact & $\mathrm{Al}_{12}(\mathrm{Fe}, \mathrm{Mn})_{3} \mathrm{Si}$ & 76.1 & 11.7 & 6.0 & 6.2 \\
& Coarse compact & $\mathrm{Al}_{12}(\mathrm{Fe}, \mathrm{Mn})_{3} \mathrm{Si}$ & 76.0 & 11.8 & 5.9 & 6.3 \\
\hline
\end{tabular}

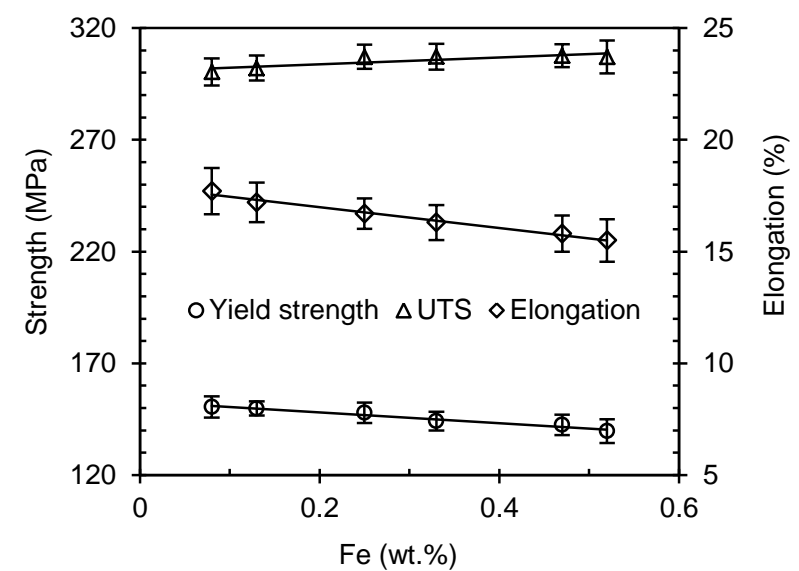

Fig. 3 Effect of $\mathrm{Fe}$ on the yield strength, ultimate tensile strength (UTS) and elongation of Al-Mg-Si-Mn diecast tensile samples.

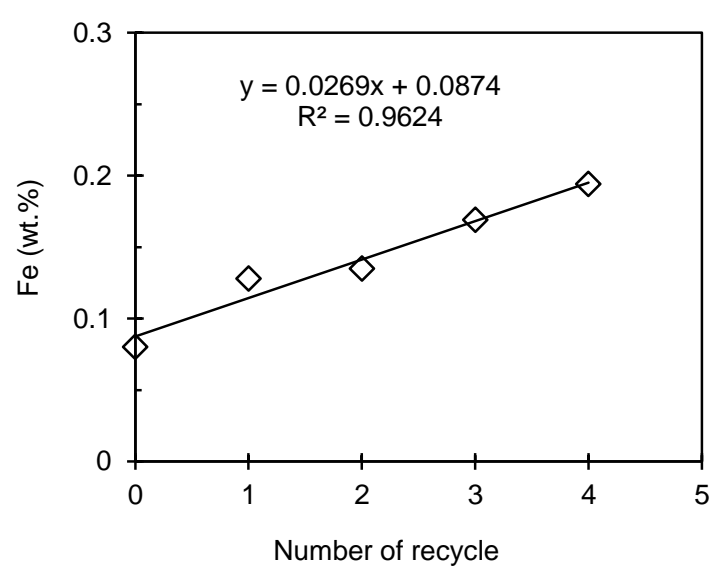

Fig. 4 The accumulation of Fe content in the recycled alloy as a function of the number of recycles.

(b) The accumulation of Fe content in the alloy made by recycled materials

In order to figure out the accumulation of Fe concentration in the diecast alloy, $40 \mathrm{~kg}$ melt was made and cast. The biscuit, runners and overflows were fully recycled. The composition was adjusted before casting. The composition of the alloy after each cycle was given in Table 2, which revealed that the main alloy elements were essentially consistent in all experiments. The accumulation of Fe content in the alloy as a function of recycle times is shown in Fig. 4. It is seen a linear increase of $\mathrm{Fe}$ content in the alloy with the increase of recycle times. The fitted equation indicates that the increase of Fe was $0.027 \mathrm{wt} . \%$ for each recycle.

Table 2 The alloy composition measured by ICP test for the alloy each recycle time

\begin{tabular}{llllllll}
\hline Recycle times & $\mathrm{Si}$ & $\mathrm{Fe}$ & $\mathrm{Mg}$ & $\mathrm{Mn}$ & $\mathrm{Ti}$ & Others & $\mathrm{Al}$ \\
\hline 0 & 1.93 & 0.082 & 5.21 & 0.59 & 0.16 & 0.10 & Bal. \\
1 & 1.94 & 0.135 & 5.20 & 0.60 & 0.17 & 0.10 & Bal. \\
2 & 1.92 & 0.138 & 5.19 & 0.60 & 0.16 & 0.11 & Bal. \\
3 & 1.92 & 0.168 & 5.23 & 0.58 & 0.14 & 0.11 & Bal. \\
4 & 1.88 & 0.191 & 5.35 & 0.55 & 0.13 & 0.12 & Bal. \\
\hline
\end{tabular}

Fig. 5 shows the microstructure of the alloy after 2 recycles and 4 recycles. It is seen no significant change in the morphologies of the primary $\alpha$-Al phase, eutectic phase and Fe-rich phase in the alloy in comparison with the results shown in Figs. 1 and 2. The SEM/EDX quantitative analysis identified the Fe-rich phase in the recycled alloys was shown in Table 3, which were the same as the Fe-rich compounds identified in the fresh alloys with different Fe levels. The typical composition of the irregular Fe-rich intermetallics was $\alpha-\mathrm{Al}_{15}(\mathrm{Fe}, \mathrm{Mn})_{2} \mathrm{Si}$ phase in the alloy after two recycles. The fine compact Fe-rich phase had the typical composition of the $\alpha$ - $\mathrm{Al}_{12}(\mathrm{Fe}, \mathrm{Mn})_{3} \mathrm{Si}$ phase in the alloy after 4 recycles. The mixed Fe-rich intermetallics of $\alpha-\mathrm{Al}_{15}(\mathrm{Fe}, \mathrm{Mn})_{2} \mathrm{Si}$ phase and 
$\alpha-\mathrm{Al}_{12}(\mathrm{Fe}, \mathrm{Mn})_{3} \mathrm{Si}$ phase were seen in the alloy after four recycles. This further confirms that the Ferich intermetallics contain higher iron in the alloy with increased iron content. Fig. 6 shows the mechanical properties of the recycled alloys as a function of the number of recycle. In the experimental range, the yield strength and UTS were essentially no change, but the ductility decreased obviously with the increase of recycle times. However, the mechanical properties were still satisfied for the recycled alloys.

Table 3 Average compositions of Fe-rich intermetallic phases of the recycled alloy by quantitative SEM/EDX analysis

\begin{tabular}{llllllll}
\hline Cycle & $\mathrm{Fe}($ wt.\%) & Phase morphology & Identified compounds & $\mathrm{Al}$ & $\mathrm{Fe}$ & $\mathrm{Mn}$ & $\mathrm{Si}$ \\
\hline 2 & 0.138 & Fine irregular & $\mathrm{Al}_{15}(\mathrm{Fe}, \mathrm{Mn})_{2} \mathrm{Si}$ & 84.9 & 5.6 & 4.6 & 4.9 \\
4 & 0.191 & Fine irregular & $\mathrm{Al}_{15}(\mathrm{Fe}, \mathrm{Mn})_{2} \mathrm{Si}$ & 84.4 & 5.8 & 4.8 & 5.0 \\
& & Fine compact & $\mathrm{Al}_{12}(\mathrm{Fe}, \mathrm{Mn})_{3} \mathrm{Si}$ & 76.1 & 10.7 & 7.0 & 6.2 \\
\hline
\end{tabular}
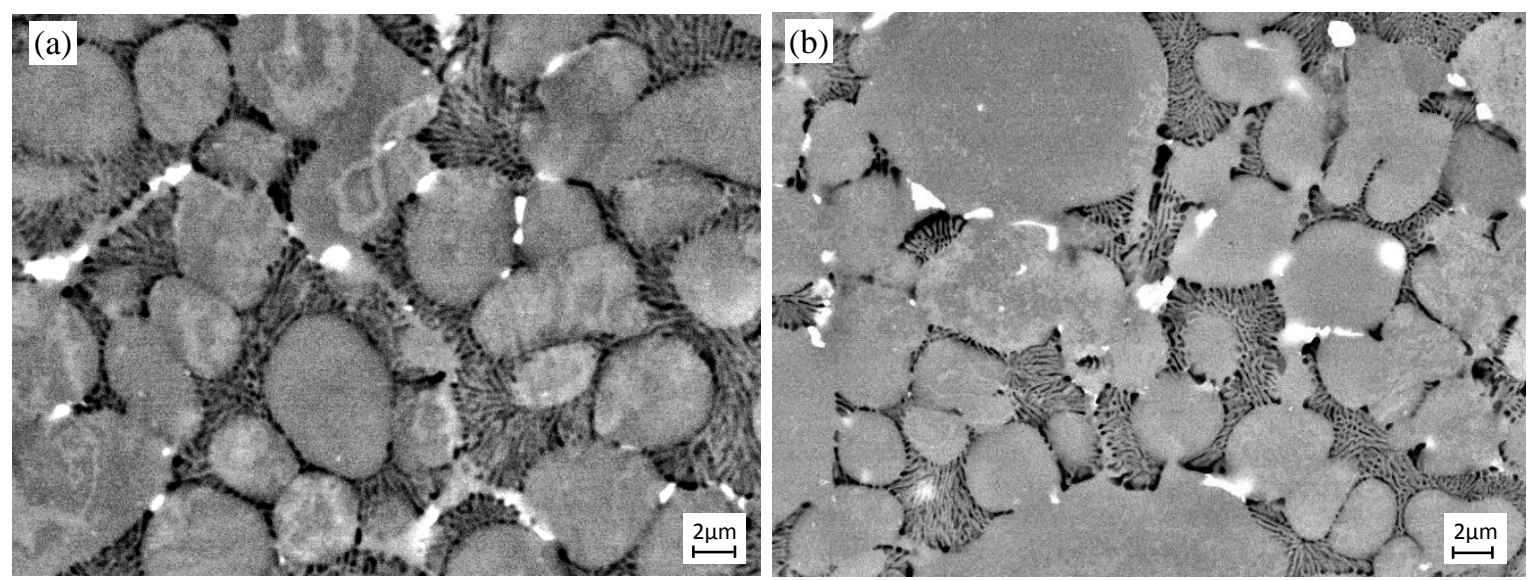

Fig.5 Backscattered SEM micrographs showing the morphology of Fe-rich intermetallics in the Al$\mathrm{Mg}-\mathrm{Si}-\mathrm{Mn}$ alloys (a) after two recycles and (b) after four recycles.
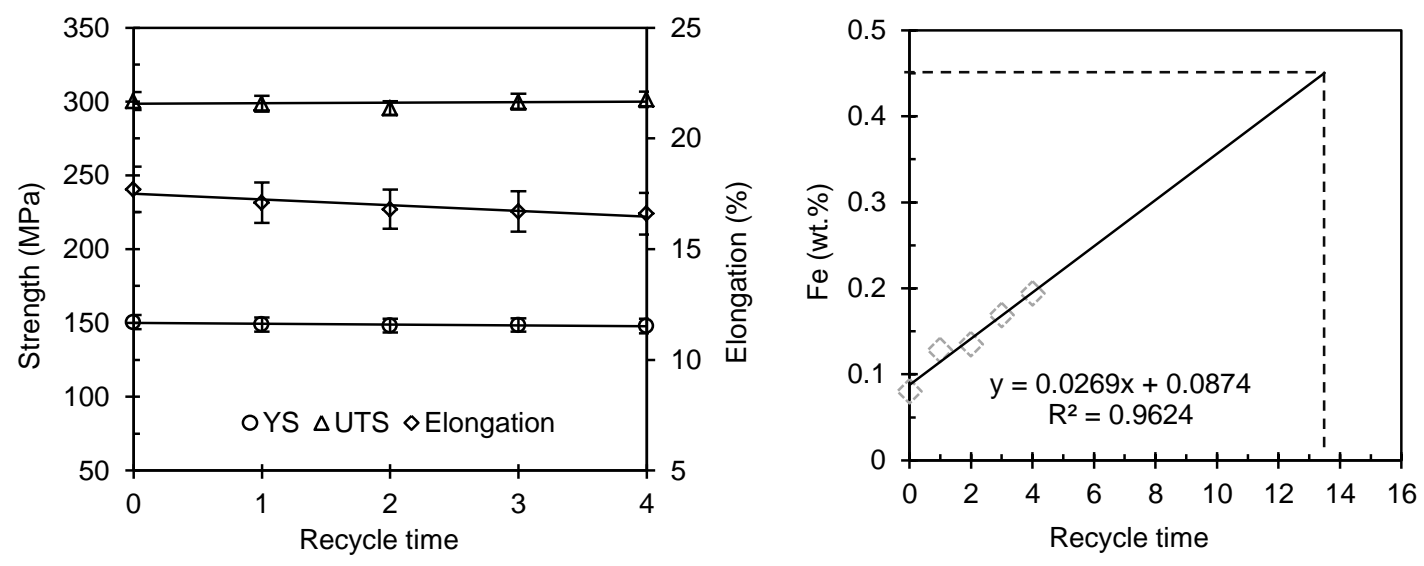

Fig.6 Effect of recycle times on the yield strength (YS), ultimate tensile strength (UTS) and elongation of $\mathrm{Al}-\mathrm{Mg}-\mathrm{Si}-\mathrm{Mn}$ diecast tensile

Fig.7 The relationship between recycle times and Fe content accumulated in the alloy. samples made by recycle materials.

(c) The prediction of recycle times for the recycled alloy

In order to find out the maximum number of recycles for the alloy to satisfy the mechanical properties, a regression of the existing data is shown in Fig.7. It is clearly seen that the Fe content was still under the limit of $0.45 \mathrm{wt} . \%$ after 13 cycles of full circulation. In production, the alloy is normally recycled with a part of fresh alloys. Therefore the cycle times should be more than 13 obtained from the fully recycled alloy. 


\section{Discussion}

Generally, the features of microstructure and the phase formation of Fe-rich intermetallics in the experiments can be explained with the equilibrium phase diagram calculated from CALPHAD [5]. The solidification process and the associated changes of liquid compositions determine the formation of different phases. From the phase diagram, the prior phase is $\alpha$-Al phase when $\mathrm{Fe}$ content is less than $0.25 \mathrm{wt} \%$. The solidification starts to form $\alpha$-Al phase in the shot sleeve, which is interrupted during die filling. The solidification of $\alpha$-Al phase continues in the die cavity, during which $\mathrm{Si}, \mathrm{Fe}$ and $\mathrm{Mn}$ elements are enriched in the remaining liquid and the Fe-rich intermetallics are consequently formed in the melt. The high cooling rate in the die cavity and the absence of superheat in the melt enhance the heterogeneous nucleation, and therefore promote the formation of fine compact $\alpha$-AlFeMnSi intermetallics. When Fe content is increased, the prior phase becomes $\alpha-$ AlFeMnSi phase. The solidification of $\alpha$-AlFeMnSi compound increases the undercooling in front of the interface of the crystal, resulting in the nucleation and growth of $\alpha$-Al phase in associated with $\alpha$-AlFeMnSi compound (Figs. 2 and 5). The solidification continues in the die cavity, where the compact $\alpha$-AlFeMnSi compound and $\alpha-\mathrm{Al}$ phase precipitate under high cooling rate. Overall, the final stage of solidification is the multi-eutectic transformation to generate the eutectic structure mainly of Al- $\mathrm{Mg}_{2} \mathrm{Si}$ phase.

Referring to the mechanical properties, the decreased yield strength is believed to correspond to the amounts of Fe-rich intermetallic compounds, which consume $\mathrm{Si}$ and $\mathrm{Mn}$ in the alloy. The fine Fe-rich intermetallics are able to provide precipitation strengthening in the alloy. Therefore, the final yield strength is the result of balance between the decreased solution strengthening and the increased precipitation strengthening. The accompanied decrease of elongation is due to the initiation of cracks by Fe-rich compounds.

The accumulation of $\mathrm{Fe}$ in the recycled alloy is steadily detrimental for the mechanical properties. However, the accumulation is a slow process, in which at least 13 cycles are needed to produce the alloy with required mechanical properties. It is worth of emphasising that this is obtained from the fully recycled alloy. In reality, the recycled materials are only a part of the alloy, which can dilute the Fe concentration. Therefore, the recycle times will be higher than the figure obtained from the fully recycled alloy in Figure 7.

\section{Conclusion}

In the experimental range, the increased $\mathrm{Fe}$ content reduces the ductility and the yield strength but slightly increase the UTS of the diecast alloy. The tolerable Fe content is $0.45 \mathrm{wt} . \%$, at which the recycled alloys are still able to produce castings with the mechanical properties of yield strength over 140MPa, UTS over 280MPa and elongation over $15 \%$.

The Fe is steadily accumulated in the alloy with the increased recycle times. However, after 13 cycles, the fully recycled alloys are still able to produce ductile alloy with satisfied mechanical properties.

\section{Acknowledgement}

The authors would like to thank the TSB (UK) for financial support.

\section{References}

[1] S. Ji, D. Watson, Z. Fan, M. White, Mater. Sci. Eng. A556 (2012)824-833.

[2] S. Ji, Y. Wang, D. Watson, Z. Fan, Metall. Mater. Trans. A 44(2013)3185-3197.

[3] J. Buffington, R. Peterson, JOM 65(2013) 941-950.

[4] G. Rombach, Acta Materialia 61(2013)1012-1020.

[5] S. Ji, W. Yang, F. Gao, D. Watson, Z. Fan, Mater. Sci. Eng. A564 (2013) 130-139. 